\title{
Effects of Multimedia-Assisted Learning on Learning Behaviors and Student Knowledge in Physical Education Lessons: Using Basketball Game Recording as an Example
}

\author{
https://doi.org/10.3991/ijet.v15i01.11393 \\ Chun-Chieh Kao ${ }^{(凶)}$, Yu-Jy Luo \\ Ming Chuan University, Taoyuan City, Taiwan \\ kao@mail.mcu.edu.tw
}

\begin{abstract}
The purpose of this study was to create a multimedia learning environment for use in PE lessons and to determine the effects of a traditional learning environment versus a multimedia learning environment on students' learning behaviors and knowledge. This study had a pretest-posttest quasiexperimental design. The control and experimental groups comprised students at a Taiwanese university who were taught using the traditional teaching method (TT group; 48 students) and TMA (TMA group; 47 students). The pretest and posttest comprised the Learning Behavior Scale in Physical Education and a test questionnaire that assessed the students' knowledge of basketball game recording methods through 32 multiple-choice questions. The teaching procedure lasted 4 weeks and covered various aspects of the rules of basketball, including the methods of recording basketball game scores. Differences between the groups were determined using various statistical tests. The students' learning behaviors and knowledge of basketball recording methods were discovered to be significantly improved in both groups at the posttest. However, the TMA group outperformed the TT group, enhancing the students' learning behaviors and knowledge to a greater degree. Overall, a combination of TT and TMA may have the most beneficial effect on students' cognition and learning. Teachers should take their students' current cognitive development into consideration when designing course materials.
\end{abstract}

Keywords - Teaching strategy, learning behaviors, teaching materials, multimedia videos

\section{Introduction}

Educators must be open to learning about their students and modifying their teaching to increase students' academic success [1]. Most of the research on Sport Education focused on competency and participation [2] and game involvement [3]. Leser et al. [4] and Huang [5] reported that although evidence on the application of multimedia courses and materials in sports training is being accumulated, empirical case studies examining the application of multimedia teaching materials in basketball game re- 
cording methods teaching are rare. The responses of PE students to such multimedia environments have not yet been thoroughly investigated [6]. Multimedia environments for the teaching and learning of such topics and skills seem to constitute a novelty, and the research on the evaluation of their effectiveness in HE institutions is still very scarce [7]. Therefore, the effectiveness of multimedia learning in PE must be assessed through empirical research; the combination of audio and visual techniques in teaching is particularly crucial to determining the effects of blended multimedia learning compared with traditional teaching.

Due to advances in computers and electronic media, the potential for quality education has been elevated with the appearance of innovative instructional methods employing multimedia equipment and resources [4]. Multimedia teaching has gradually substituted traditional teaching [8], the traditional PE teaching mode hasn't met the requirements of $\mathrm{PE}$ teaching activities in schools, resulting in development bottlenecks in teaching management, sports facilities and teaching scale [9]. The E-learning should try to lay more stress on physical education since sports activities are placed importance on our daily lives progressively and can strengthen someone's mind and body [6]. The key elements of multiple media, user control over the delivery of information, and interactivity can be used to enhance the learning process through creating integrated learning environments [10]. Thus, multimedia-centered teaching could soon become a major means of information delivery and knowledge accumulation as well as a crucial learning situation in PE learning.

\section{Theoretical Background}

The term "multimedia" in its current definition emerged at the end of the 1980s and was adapted from marketing into educational psychology [11]. Multimedia technology is a technology using computer to deal with the information of texts, graphics, images, sounds, animations and videos to establish logic relations and interaction between human and computer [12]. On the basis of this definition, we employed two influential theoretical multimedia-learning frameworks and a theoretical model to examine the research questions and hypotheses of this study.

Integrating the Paivio's "dual code" theory of human cognition [13] and Baddeley's model of human working memory [14], Mayer [15] proposed multimedialearning theory. This theory holds that in multimedia learning, information is presented using text and images and that true understanding is achieved when this information is combined with pre-existing long-term knowledge. According to Mayer and Moreno [16], the human cognitive system allocates resources and handles incoming multimedia messages in a multimedia-learning situation in the following manner:

- Consistent mental representations are established by diverting attention to specific information and organizing the selected information

- Active learning is then achieved by integrating the mental representations into other knowledge. 
Thus, learning and memorization are more effective when text and visual effects are employed. The use of both text and visual effects has a positive effect on learning performance [17,18] and may be one of the factors affecting the learning process [19].

Another influential theoretical multimedia-learning framework is cognitive load theory [20]. This theory holds that three sources of cognitive load exist [21,22]:

- Intrinsic

- Extraneous and

- Germane cognitive loads

The amount of interaction in a particular teaching situation and the level of difficulty of this interaction produce different levels of cognitive load on the working memory of learners [23]. Appropriate presentation of teaching materials can reduce the extraneous cognitive load and help learners focus on the learning content [24,25]. Cognitive load theory has become a critical theoretical framework for analyzing the cognitive process and teaching design. To help learners achieve higher learning performance, the designers of teaching plans should strive to reduce the internal and extraneous cognitive load on learners while enhancing their germane cognitive load.

Multimedia learning is one of the future development trends in the field of education. Multimedia materials are crucial means of information delivery from teachers to students and can be used to overcome the inadequacy of the traditional teaching method. Teaching processes that integrate appropriate visual and auditory materials can reduce students' cognitive load during learning, easily attract learners' attention, and consequently enhance learning performance [26]. The current study employed the theoretical frameworks of multimedia-learning theory [15] and cognitive load theory. These two theories assert that appropriate design of learning materials can produce meaningful learning. The utilization of multimedia-assisted teaching (TMA) strategies can lead to thorough acquisition of knowledge, helping learners achieve their learning goals.

\subsection{Potential and hurdles of TMA}

The consequences of adding auditory or visual materials to the traditional PE teaching materials and visually delivering PE information are unclear. Research into cognition has demonstrated that visual information accounts for $80 \%$ of human functioning, whereas auditory information accounts for only 13\% [27]. This indicates that the amount of visual information surpasses the amount of other sensory information. Accordingly, the use of visually assisted teaching should help students quickly achieve understanding during the learning process [28,29]. The main advantages of applying multimedia technology in physical education teaching are mainly embodied in three aspects [30-32], as follow:

- Improvement of students' interest

- Improve of the learning effects

- Effective combination of multimedia and physical education teaching 
More specifically, multimedia materials are regarded as critical elements in the presentation of PE education content and are considered major PE teaching mediums [33,34]. Numerous studies [35-37] have demonstrated that integrating information technology into PE teaching is worthwhile because such integration offers greater variety in information presentation for PE teaching [38].

Use of multimedia teaching can improve the efficiency of teaching processes [39] and lead to active learning [40]. The efficiency of teaching processes is also closely related to the interaction between learning motivation and cognition [41]. A study examining the use of multimedia in teaching revealed that for some teachers, integrating multimedia into teaching is a heavy burden [42]. Some teachers believe that multimedia teaching is inconvenient and do not know how to utilize information technology in their teaching [43]. The results of Kretschmann [44] revealed that teacher age is a factor significantly affecting the computer technology skills of teachers: younger teachers typically have superior computer technology skills. A recent study conducted by Robinson and Randall [45] revealed that the technical obstacles frequently faced by PE teachers when using audiovisual technology include time constraints, professional knowledge, and obtaining resources. Nevertheless, most of the PE educators in the study believed that audiovisual technology has great application potential in the field of education. As aforementioned, TMA has great potential in PE education. The means of multimedia material presentation are a crucial aspect of TMA. When designing multimedia teaching materials, the characteristics and limitations of memory and cognitive processes should be taken into consideration. Additionally, factors such as the instructors' professional knowledge, technical ability, and resource-obtaining ability should be considered, so that the optimal student learning mode can be identified. TMA may not be suitable for all academic courses and goals, but it can be employed in almost all academic courses to enrich the teaching approach. For instructors, TMA offers both a challenge and an opportunity.

\subsection{Learning behaviors in PE lessons}

Teachers and students are the two main subjects involved in classroom lessons [46]. Learning behaviors are especially crucial in the classroom setting because they serve as a behavioral approach to students' subsequent learning and development [47]. This study using the learning behaviors perspective of Chen [48] as a framework, we defined learning behaviors using three indicators:

- Learning motivation

- Learning methods

- Sports attitude

Learning motivation is a type of mental process that triggers an individual to engage in a learning activity, sustain a learning activity, and move toward set learning targets; in other words, learning motivation drives individuals to advance toward their goals [49]. Bandura [50] in his social cognitive theory, argues that self-efficacy beliefs (i.e., what people believe about their capabilities) have a stronger influence on the motivation to perform a particular action than actual skills, knowledge, or previ- 
ous accomplishment. Models of motivation also include the concepts of effort and persistence, which have been traditionally named as motivated learning behavior $[51,52]$. In addition to giving students the knowledge and experience they require, university education triggers students' motivation to autonomously participate and engage in learning [53]. Differences in learning ability and learning motivation are often regarded as factors for predicting learning effectiveness [54]. More specifically, an individual's success or failure in learning is affected by his or her level of learning motivation [55].

Other than attitude toward learning strategies, university students' choice of learning methods is dependent on their intrinsic motivation, extrinsic motivation, and willingness to learn [56]. When students have high learning motivation, they efficiently complete meaning-learning activities [49]. When effective teaching strategies are employed, learning performance is enhanced [57]. More specifically, learning performance is positively correlated to the learning method selected [58]. In addition to choice of learning strategy, learners' choice of learning method directly affects their learning performance; students must learn to employ the appropriate learning method to enhance their learning performance [59]. Because a close relationship exists between learning method used and learning efficiency, learning methods are considered a critical predictor of learning performance.

The enhancement of positive attitudes is one of the key components that impacts student learning $[60,61]$. Sports attitude refers to the positive or negative attitude held by students toward PE classes in school, and this attitude partially affects student behavior, even influencing the willingness of students to participate in physical activities [62]. In the other words, the creation of a positive learning environment impacts both student attitudes and student learning [63]. Physical education, therefore, can serve as a medium to influence student attitudes toward physical activity since it has the potential to reach most children [64]. The results of both traditional conceptual studies and empirical studies have revealed an impartial connection between sports attitude and learning performance [65]. The cognitive and affective components of PE strongly affect overall learning attitude [66]. Thus, creating an appropriate PE learning environment is vital, because such an environment enhances learning performance.

As aforementioned, not only can effective teaching strategies lead to the change of learning methods in the learning process [67], they can also establish a positive learning attitude, generate meaningful learning processes, and enhance learning performance $[68,69]$. The methods employed by instructors to help learners maintain their learning motivation affect the learners' subsequent retention and retrieval of knowledge. Additionally, method selection is crucial in cultivating students' positive attitude toward PE lessons. Learning motivation, learning methods, and learning attitude are the three indispensable components of learning performance; they supplement and complement each other, and they are all integral to ensuring optimal learning performance. 


\subsection{Research hypotheses}

The purpose of this study was to create a multimedia-learning environment for use in PE lessons and determine the effects of a traditional learning environment versus a multimedia-learning environment on students' learning behaviors and acquired knowledge of basketball game recording methods. More specifically, we had the following objectives. First, we wished to analyze the combined impact of traditional teaching and TMA on learning behavior and acquired knowledge of basketball game recording methods (within effect). Second, we aimed to compare the learning behavior and the knowledge of basketball game recording methods of students between traditional teaching (TT) and TMA (between effects). On the basis of the aforementioned influencing factors and literature review, this study proposed that TMA enhances student learning behavior and acquired knowledge of basketball game recording methods. Therefore, we proposed two research hypotheses, as follows:

- Hypothesis 1: Students' learning behavior and knowledge of basketball game recording methods are significantly improved under the TMA.

- Hypothesis 2: The TMA Students' learning behavior and knowledge of basketball game recording methods are significantly better than the TT.

\section{Methodology}

\subsection{Research design}

The present study employed the nonequivalent pretest-post-test quasi-experimental design with an experimental group, which received the TMA, and a control group, which received the TT. In consideration of ethical research, the research content, research activity design, feedback process for participants, possible harm or discomfort that may be experienced during the research, protection of privacy and information for participants, and freedom for participants to withdraw at any time were disclosed. Before initiation of the experimental teaching sessions, both groups completed the pretest: The Learning Behavior Scale in Physical Education (LBSPE) and the test questionnaire, which assessed the students' perception of basketball game recording methods. In the fifth week, students took the posttest, which comprised the same questionnaires administered in the pretest. All procedures, including the informed consent and the recruitment of participants, were reviewed and approved by the Thai Clinical Trials Registry Committee (TCTR), and was satisfactory for all items of Trial Registration Data Set required by the World Health Organization. The identification number for the clinical trial in this study is TCTR20190414001.

\subsection{Participants}

The research was conducted at Ming Chuan University of Taiwan which has 95 students. The code of basketball course is 02412 and 02406 in semester 2 academic year 2018/2019. In the research process, it does not create a new class group but an 
existing class group is then selected to determine the experimental class and the control class that has almost the same characteristics. The sample comes from two classes. One class was used for the experimental group of 47 students (35 male and 12 female, with an average age of $21.85 \pm 0.51$ years); one for the control group of 48 students (43 male and 5 female, with an average age of $22.21 \pm 0.71$ years). The courses of knowledge of basketball game recording methods last for 4 weeks in one semester with each classroom meeting once a week for 50 minutes (Figure 1).

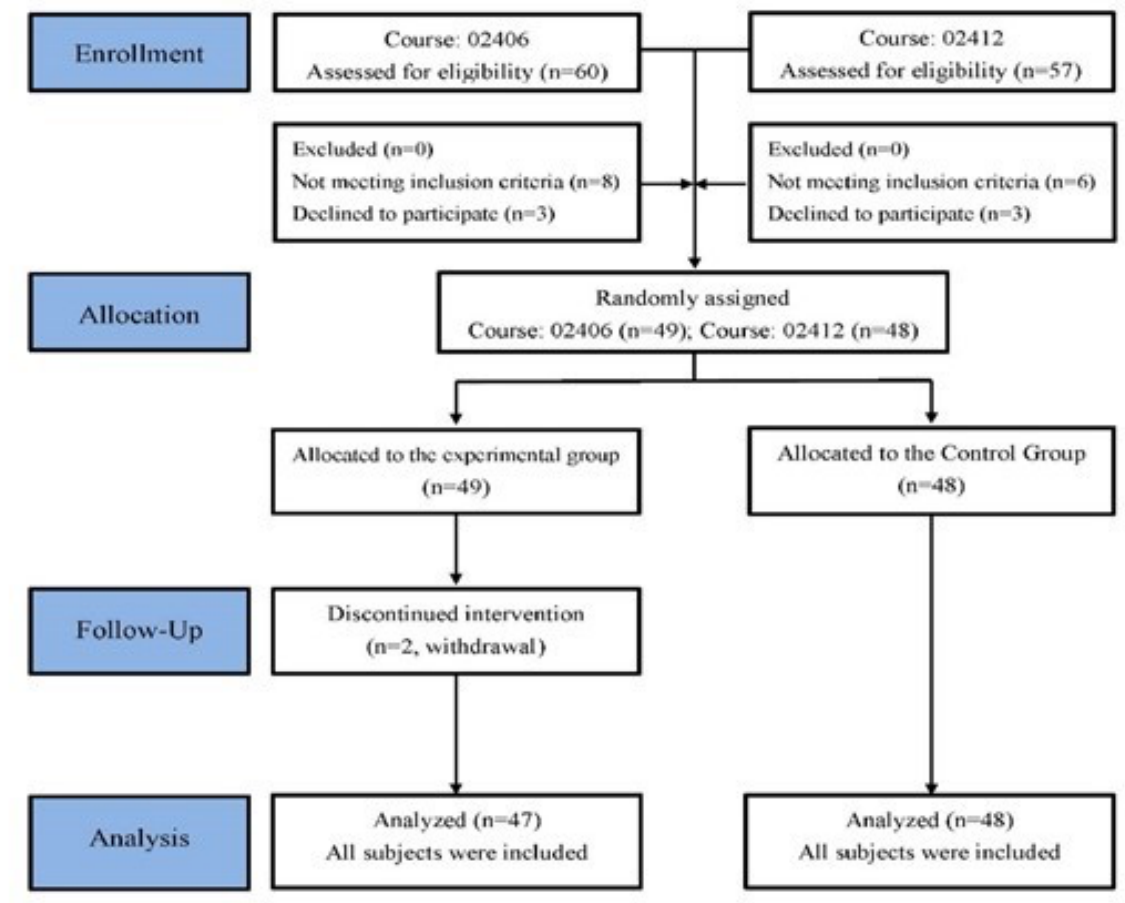

Fig. 1. Flowchart of the study's sampling process

\subsection{Ideas for course design}

We split the learning content into several smaller segments according to the segmentation multimedia design principle proposed by Mayer and Moreno [16]; the purpose was to reduce the amount of information presented in each session. Using the official basketball rules published by FIBA [70] as a framework, the teaching sessions for the experimental group were conducted using a TMA approach. By contrast, the control group was taught according to the direct instruction procedures suggested by Rosenshine [71]. The objectives and the structures of the course are presented in Table 1 . 
Table 1. Designing learning materials for educational objectives

\begin{tabular}{|c|c|c|c|}
\hline Week & Experimental group & Control group & Educational objectives \\
\hline Week1 & $\begin{array}{l}\text { 1)FIBA Scoresheet } \\
\text { 2)TMA } \\
\text { 3)120 seconds media }\end{array}$ & $\begin{array}{l}\text { 1)FIBA Scoresheet } \\
\text { 2)TT }\end{array}$ & \multirow{4}{*}{$\begin{array}{l}\text { 1.Cognitive goals } \\
\text { 1)Learn about the preservation of } \\
\text { records } \\
\text { 2)Understand the skills of com- } \\
\text { petition recording } \\
\text { 2.Affective goals } \\
\text { 1)Understand the norms of } \\
\text { recording methods. } \\
\text { 2)Learn the recording methods. } \\
\text { 3.Psychomotor goals } \\
\text { 1)Learn the recording skills }\end{array}$} \\
\hline Week2 & $\begin{array}{l}\text { 1)Teams on the scoresheet } \\
\text { 2)TMA } \\
\text { 3)175 seconds media }\end{array}$ & $\begin{array}{l}\text { 1)Teams on the scoresheet } \\
\text { 2)TT }\end{array}$ & \\
\hline Week3 & $\begin{array}{l}\text { 1)Officials' signals } \\
\text { 2)TMA } \\
\text { 3)160 seconds media }\end{array}$ & $\begin{array}{l}\text { 1)Officials’ signals } \\
\text { 2)TT }\end{array}$ & \\
\hline Week4 & $\begin{array}{l}\text { 1)Running score } \\
\text { 2)TMA } \\
\text { 3)180 seconds media }\end{array}$ & $\begin{array}{l}\text { 1)Running score } \\
\text { 2)TT }\end{array}$ & \\
\hline
\end{tabular}

\subsection{Development of teaching materials}

The teaching materials used in this study were developed on the basis of the Official Basketball Rules published by FIBA [70]. Two professional basketball referees and one multimedia teacher were recruited to the teaching material development group, and two focus meetings were held to determine the design of the teaching materials. Multimedia instructional videos containing information about basketball game recording methods and rules were later developed on the basis of the results of the meetings. A total of four teaching units were developed on the respective topics of the scoresheet, teams on the scoresheet, officials' signals, and running score. The audio/video presentation of each of the units was approximately 125 to 180 seconds in length and media was rendered into a MP4 format (Figure 2).
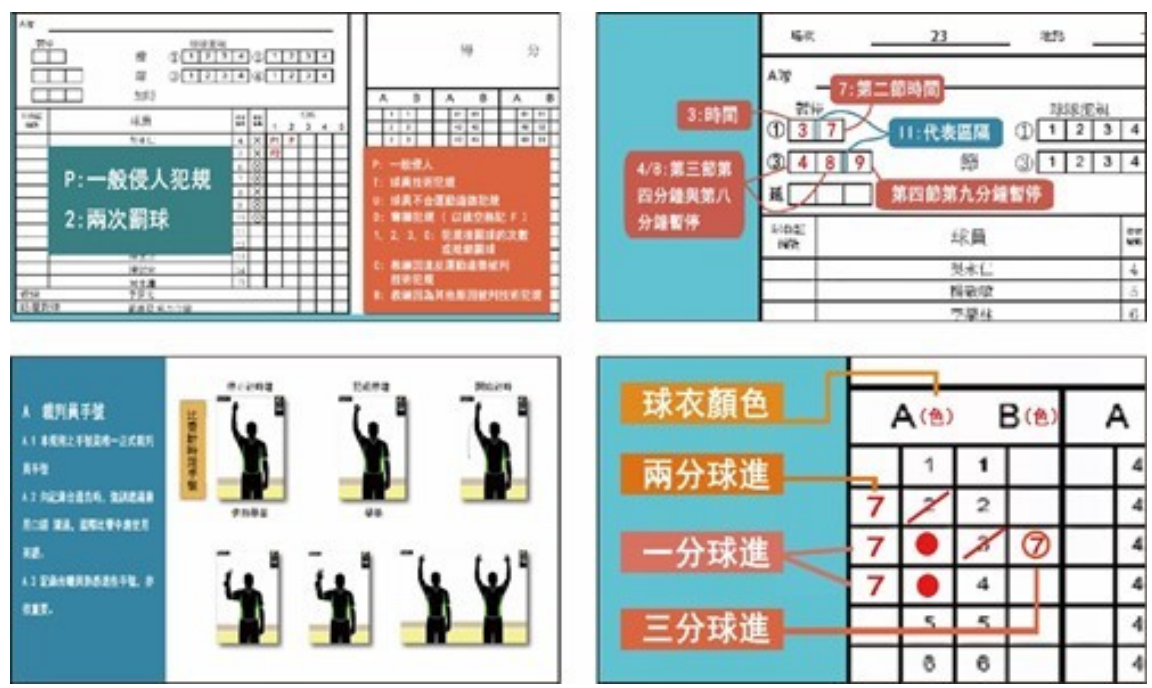

Fig. 2. Screen capture of the multimedia videos 


\subsection{Procedures}

First, university students in two basketball elective classes were recruited. The students were then filtered according to the inclusion and exclusion criteria. The selected students were randomly divided into two groups (i.e., experimental and control groups). Both groups received training on the topic of basketball game recording methods. However, in the training sessions of the experimental group, a TMA blended teaching approach was used, whereas in those of the control group, only the TT approach was employed. Before the commencement of the study, the researchers briefed the students about the purposes and procedures of the research. The students were explicitly told that their anonymity would be guaranteed and that they were free to choose whether to participate. If the students agreed to participate, they were requested to sign the consent form. Before the commencement of the teaching procedures, the students were required to fill in a demographic questionnaire and complete the pretest. The teaching procedure lasted 4 weeks, and four teaching units were taught. The teaching sessions in the first week introduced the scoresheet and its development history, whereas those in the second week focused on the completion of team record forms. The sessions in the third week addressed the signals made by basketball game referees, and finally, the sessions in the fourth week discussed the methods for recording running scores. In the fifth week, the students took tests that assessed their learning behaviors and acquired knowledge of basketball game recording methods.

\section{$4 \quad$ Research Tools}

\subsection{Learning behavior scale in physical education (LBSPE)}

The LBSPE could access students' learning behavior in physical education. Learning behavior referred to students' individuals' capabilities to perform their learning motivation, learning method, learning attitude in physical education. This LBSPE scale took reference from the scales developed by Chen [48] and Kao [72] and comprised a total of 11 items (incl. Learning motivation, learning method, learning attitude) analyzing three dimensions. The LBSPE that was used in the present study had been revision, and three focus group meetings were held to revise the items. Two college students were selected to complete the scale and check it well. Subsequently, the LBSPE was tested for validity and reliability through confirmatory factor analysis. The study samples comprised 277 students through purposive sampling who correctly completed the LBSPE. The result showed acceptable fit $\left(\chi^{2}=217.80, p<0.05\right.$; RMSEA $=0.05, \mathrm{AGFI}=0.84, \mathrm{CFI}=0.96$ ). The average variance extracted (AVE) of the latent variable was 0.75 , with a composite reliability (CR) of 0.92 . Thus, we concluded that the LBSPE was psychometrically sound, with adequate reliability and validity. 


\subsection{Test questionnaire for assessing acquired knowledge of basketball game recording methods}

In this study, the test questionnaire used to assess the participants' acquired knowledge of basketball game recording methods was developed on the basis of the test questionnaire devised by Kao and Yang [73] for assessing knowledge of basketball game recording strategies. At the pretesting stage, 184 students were recruited. Appropriate test items were identified using the following evaluation criteria:

- Item difficulty index of $0.8>\mathrm{P}>0.2$

- Item discrimination index of $\mathrm{D}>0.2$

A test questionnaire containing 32 test items was finalized. Regarding the properties of the final test questionnaire, the item difficulty index of the items ranged from 0.23 to 0.75 ; the average difficulty was 0.63 . The item discrimination index of the test items ranged from 0.47 to 0.71 ; the average item discrimination index was 0.38 . The questionnaire was used to assess the level of participants' acquired knowledge of basketball game recording methods. Each question contained four answer options, only one of which was correct. The time limit for the administration of this test questionnaire was 32 minutes. One point was awarded for each correctly answered question, and the maximum score possible was thus 32 points. A high score indicated more acquired knowledge of basketball game recording methods.

\subsection{Data analysis}

The Statistical Product and Service Solutions software package was employed to calculate the statistics with respect to data processing, and five analytical methods were applied to the results:

- Descriptive statistics were applied to analyze the distributions of the height, weight, and body mass index (BMI) of participants

- Chi-square testing was used to conduct a homogeneity test on the gender of participants

- Independent-samples t testing was used to analyze the homogeneity of the height, weight, and BMI of participants

- Analysis of covariance (ANCOVA) was applied to compare and analyze the experimental and control groups in terms of learning behavior and knowledge of basketball game recording methods post-test results after excluding the influence of pretest scores

- Based on the standard proposed by Cohen [74], the $\eta 2$ (eta squared) was used for ANCOVA, and the thresholds were set to $\leq 0.02$ for small, 0.059 for medium, and $\geq 0.138$ for large. The significance levels for all statistical tests in this study were set to $\alpha<0.05$. 


\section{$5 \quad$ Results}

\subsection{Homogeneity test between the experimental and control group}

The analyses results for the demographic analyses indicated that there were no significant differences between the groups in terms of age $(\mathrm{t}=2.80, \mathrm{p}>0.05, \mathrm{~d}=0.58)$, weight $(\mathrm{t}=1.13, \mathrm{p}>0.05, \mathrm{~d}=0.09)$, height $(\mathrm{t}=0.45, \mathrm{p}>0.05, \mathrm{~d}=0.23)$ and body mass index $(\mathrm{t}=1.66, \mathrm{p}>0.05, \mathrm{~d}=0.34)$. In addition, in terms of the gender $\left(\mathrm{x}^{2}=3.69, \mathrm{p}>\right.$ $0.05, \mathrm{~d}=0.40$ ) distributions for the two groups suggesting that the two groups were homogenous. Table 2 summarizes the demographic characteristics and physical fitness of the participants in the two groups.

Table 2. Demographic characteristics of the participants

\begin{tabular}{|l|c|c|c|}
\hline \multicolumn{1}{|c|}{ Variable } & Experimental group $(\boldsymbol{n}=\mathbf{4 7})$ & Control group $(\mathbf{n}=\mathbf{4 8})$ & Total $(\mathbf{n}=\mathbf{9 5})$ \\
\hline Gender $(\mathrm{M}: \mathrm{F})$ & $35: 12$ & $43: 5$ & $47: 48$ \\
\hline Age $($ years $)$ & $21.85[0.51]$ & $22.21[0.71]$ & $22.03[0.64]$ \\
\hline Height $(\mathrm{cm})$ & $170.69[9.20]$ & $169.96[6.51]$ & $170.32[7.92]$ \\
\hline Weight $(\mathrm{kg})$ & $63.00[12.96]$ & $66.31[15.45]$ & $64.67[14.29]$ \\
\hline BMI $\left(\mathrm{kg} / \mathrm{m}^{2}\right)$ & $21.49[3.30]$ & $22.84[4.51]$ & $22.17[4.00]$ \\
\hline
\end{tabular}

Table 3 presents the results of homogeneity tests for the within-group regression. coefficients between LBSPE score and acquired knowledge of basketball game recording methods. The regression line slope of LBSPE score $\left(F=0.49, p=.49, \eta^{2}=\right.$ $.01)$ is identical to that of the acquired knowledge score $\left(F=2.46, p=.12, \eta^{2}=.03\right)$. Thus, the pretest results do not differ from the posttest results because of differences in the treatment levels of the independent variables. The assumption of homogeneity of regression slopes is therefore met, and further covariance analyses were conducted.

Table 3. Learni Homogeneity test results for within-group regression coefficients of LBSPE score and acquired knowledge score

\begin{tabular}{|l|l|c|c|c|c|c|}
\hline \multicolumn{1}{|c|}{ Variation } & \multicolumn{1}{|c|}{ Source } & Type III SS & df & $\boldsymbol{F}$ & $\boldsymbol{p}$ & $\boldsymbol{\eta}^{\mathbf{2}}$ \\
\hline \multirow{2}{*}{ Learning Behavior } & Group*Pre-test & 0.06 & 1 & 0.49 & .49 & .01 \\
\cline { 2 - 7 } & Error & 10.57 & 91 & & & \\
\hline Acquired knowledge & Group*Pre-test & 38.19 & 1 & 2.46 & .12 & .03 \\
\hline & Error & 1410.82 & 91 & & & \\
\hline
\end{tabular}

${ }^{*} p<.05$

\subsection{Learning behavior of the experimental and control groups}

As shown in Table 4 and Figure 3, the learning behavior scores of the students at the learning motivation, learning method, learning attitude and total score in the experimental group were 2.99 (adjusted mean $=3.00$ ), 3.26 (adjusted mean $=3.26$ ), 3.31 (adjusted mean $=3.30$ ) and 3.20 (adjusted mean $=3.21$ ), respectively. The scores of the students at the learning motivation, learning method, learning attitude and total 
score in the control group were 2.29 (adjusted mean $=2.29$ ), 2.48 (adjusted mean $=$ $2.48), 2.63$ (adjusted mean $=2.64)$, and 2.52 (adjusted mean $=2.52)$, respectively.

Table 4. Descriptive statistics of the learning behaviors of the experimental and control groups

\begin{tabular}{|l|l|c|c|c|}
\hline \multicolumn{1}{|c|}{ Group } & \multicolumn{1}{|c|}{ Source } & Pre-test (SD) & Pro-test (SD) & Adjusted Mean \\
\hline \multirow{4}{*}{ Experimental (TMA) } & Learning Motivation & $2.35(0.63)$ & $2.99(0.57)$ & $3.00(0.91)$ \\
\cline { 2 - 5 } & Learning Method & $2.43(0.41)$ & $3.26(0.40)$ & $3.26(0.57)$ \\
\cline { 2 - 5 } & Learning Attitude & $2.82(0.47)$ & $3.31(0.36)$ & $3.30(0.52)$ \\
\cline { 2 - 5 } & Learning Behavior & $2.51(0.32)$ & $3.20(0.32)$ & $3.21(0.50)$ \\
\hline \multirow{5}{*}{ Control (TT) } & Learning Motivation & $2.44(0.73)$ & $2.29(0.68)$ & $2.29(0.90)$ \\
\cline { 2 - 5 } & Learning Method & $2.41(0.44)$ & $2.48(0.38)$ & $2.48(0.57)$ \\
\cline { 2 - 5 } & Learning Attitude & $2.95(0.47)$ & $2.63(0.35)$ & $2.64(0.51)$ \\
\cline { 2 - 5 } & Learning Behavior & $2.57(0.35)$ & $2.52(0.36)$ & $2.52(0.49)$ \\
\hline
\end{tabular}

The results presented in Tables 4 and 5 indicate that after controlling for the influence of the covariate variables (i.e., pretest results) on the dependent variables (i.e., posttest results), both the experimental and control groups demonstrated significant improvement in learning motivation $\left(\mathrm{F}=30.72, \mathrm{p}<.05, \eta^{2}=.25\right)$, learning method $(\mathrm{F}$ $\left.=92.08, \mathrm{p}<.05, \eta^{2}=.50\right)$, learning attitude $\left(\mathrm{F}=80.12, \mathrm{p}<.05, \eta^{2}=.47\right)$, and overall learning behavior $\left(\mathrm{F}=96.55, \mathrm{p}<.05, \eta^{2}=.51\right)$ in the posttest compared with the pretest. These findings have relatively high explanatory power. Post hoc comparisons conducted using the adjusted mean values indicated that the experimental group had higher learning motivation $(3.00>2.29)$ and superior learning method $(3.26>2.48)$, learning attitude $(3.30>2.64)$, and overall learning behavior $(3.21>2.52)$ than the control group.

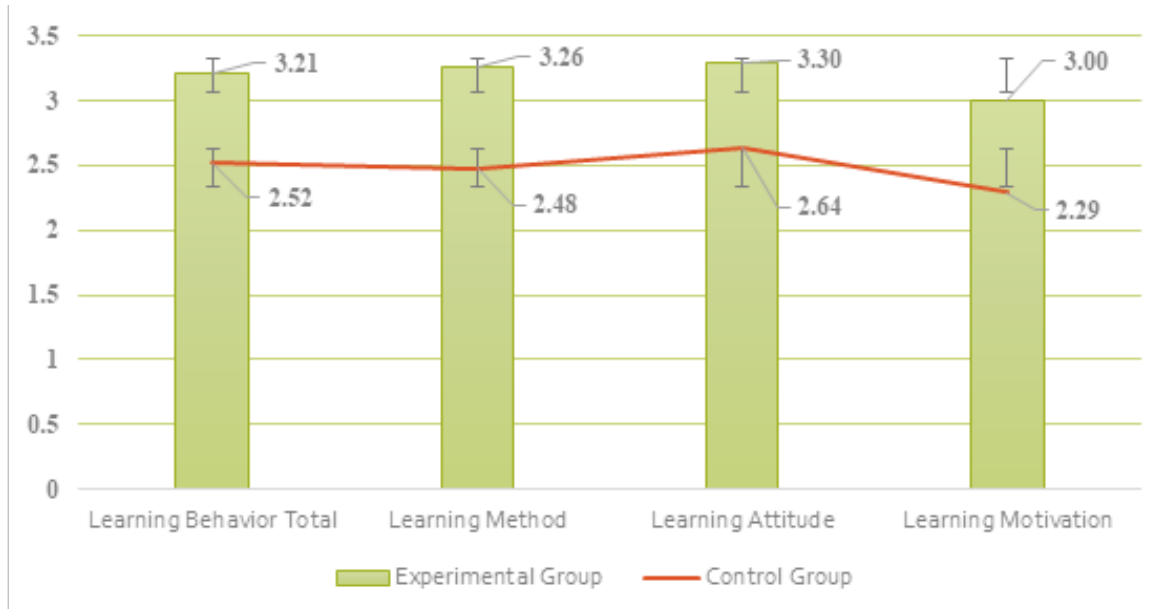

Fig. 3. Learning behavior performance between experiment group and control group 
Table 5. Covariance analysis results of learning behaviors

\begin{tabular}{|l|l|c|c|c|c|c|}
\hline \multicolumn{1}{|c|}{ Variation } & Source & Type III SS & df & F & p & $\boldsymbol{\eta}^{\mathbf{2}}$ \\
\hline \multirow{2}{*}{ Learning Motivation } & Group & 11.88 & 1 & $30.72^{*}$ & .00 & .25 \\
\cline { 2 - 7 } & Error & 35.57 & 92 & & & \\
\hline \multirow{2}{*}{ Learning Method } & Group & 14.30 & 1 & $92.08^{*}$ & .00 & .50 \\
\cline { 2 - 8 } & Error & 14.30 & 92 & & & \\
\hline \multirow{2}{*}{ Learning Attitude } & Group & 10.06 & 1 & $80.12^{*}$ & .00 & .47 \\
\cline { 2 - 8 } & Error & 11.55 & 92 & & & \\
\hline \multirow{2}{*}{ Learning Behavior } & Group & 11.15 & 1 & $96.55^{*}$ & .00 & .51 \\
\cline { 2 - 7 } & Error & 10.63 & 92 & & & \\
\hline
\end{tabular}

${ }^{*} p<.05$

\subsection{Group differences in acquired knowledge of basketball game recording methods}

As demonstrated in Table 6, the experimental group students scored 9.04 on the pretest and 24.19 on the posttest assessing knowledge of basketball game recording methods (adjusted mean $=24.20$ ). By contrast, the control group students scored 9.25 on the pretest and 21.54 on the posttest (adjusted mean $=21.54$ ).

Table 6. Descriptive statistics of the experimental and control groups' scores for acquired knowledge of basketball game recording methods

\begin{tabular}{|l|l|l|l|l|}
\hline \multicolumn{1}{|c|}{ Group } & \multicolumn{1}{c|}{ Source } & \multicolumn{1}{c|}{ Pre-test (SD) } & \multicolumn{1}{c|}{ Pro-test (SD) } & Adjusted mean \\
\hline Experimental (TMA) & Acquired knowledge & $9.04(3.67)$ & $24.19(4.36)$ & $24.20(0.58)$ \\
\hline Control (TT) & Acquired knowledge & $9.25(3.21)$ & $21.54(3.52)$ & $21.54(0.57)$ \\
\hline
\end{tabular}

The results displayed in Tables 6 and 7 indicate that after controlling for the influence of the covariate variables (i.e., pretest results) on the dependent variables (i.e., posttest results), both groups demonstrated significant improvement in their knowledge of basketball game recording methods $\left(F=10.65, p<.05, \eta^{2}=.10\right)$; the results have high explanatory power. A post hoc comparison conducted using the adjusted mean values and indicated that the experimental group (adjusted mean = 24.20) obtained higher knowledge scores than the control group (adjusted mean = 21.54).

Table 7. Covariance analysis of acquired knowledge of game recording methods

\begin{tabular}{|c|l|c|c|c|c|c|}
\hline Variation & Source & Type III SS & df & F & p & $\boldsymbol{\eta}^{\mathbf{2}}$ \\
\hline Acquired knowledge & Group & 167.75 & 1 & $10.65^{*}$ & .00 & .10 \\
\cline { 2 - 8 } & Error & 1449.01 & 92 & & & \\
\hline
\end{tabular}

$* p<.05$ 


\section{Discussion}

This study examined the effects of TMA on learning behaviors in PE lessons and acquired knowledge of basketball game recording methods. The results demonstrated that a TMA interventional PE course improved the learning behaviors and knowledge of the students. This finding is similar to those of previous studies $[4,31,75]$ - that computer multimedia technology has a considerable beneficial effect on PE education. The results of these studies also support the viewpoints of Brown et al. [76] and Milos et al. [77]. These scholars reported that TMA has a positive influence on learning motivation during PE lessons; leads to changes in learning methods; results in a positive learning experience during PE lessons; and enhances students' learning attitude, making them more willing to participate in learning. The students enrolled in the present study demonstrated significant improvement in their knowledge of basketball recording methods after the implementation of the TMA basketball course; this result indicates that compared with the TT approach, TMA is more effective when teaching basketball recording methods. This finding is similar to those of Antoniou et al. [78] and Papastergiou and Gerodimos [6], who reported that compared with TT, TMA more effectively enhanced students' acquisition of basketball knowledge. Additionally, TMA was discovered to result in superior knowledge retention compared with TT. Therefore, the two hypotheses of the current study were supported: students' learning behaviors and knowledge of basketball recording methods were significantly improved when the students were taught with TMA, and TMA was superior to TT in enhancing students' learning behaviors and knowledge.

From the perspective of learning behaviors, learning motivation is necessary to trigger a positive learning attitude and the activation of learning methods in learners. TMA is designed to induce active learning through visual stimulation. The results of relevant studies have indicated that when PE lessons are taught in a multimedia environment, learning motivation is enhanced [5], as is learning attitude [4,79]. When PE lessons taught in such an environment, effective knowledge construction is supported, ultimately leading to the generation of meaningful learning behaviors and methods $[80,81]$. When TMA is used in conjunction with TT, the two teaching approaches can supplement and complement each other. When TT is used as the main teaching approach and multimedia teaching is used as the supplementary teaching approach to extend the learning scope, favorable results can be obtained; this indicates that both teaching methods can be utilized fully and effectively when they are integrated. TMA reinforces the overall learning behaviors in PE lessons. In TMA, the teacher's teaching philosophy and materials can be integrated using multimedia technology and be presented to learners in an active and lively way through different forms of media, including text, diagrams, videos, animations, audio, and video. The various forms of media materials available in multimedia teaching can meet the needs of students with different learning styles and more fully immerse students in their learning of the curriculum. Additionally, TMA offers opportunities for teacher-student visual contact and interaction, potentially shortening the psychological gap between teachers and students. Lastly, TMA enables teachers to gain better understanding of the methods used by students to learn in a particular environment, and this could in turn enhance 
the teachers' performance. In summary, digital multimedia learning is a learning tool that promotes effectiveness of the learning process. However, according to the results of van Merriënboer and Sweller [25], excessive sensory stimulation can lead to sensory overload and confusion in the stimulation receivers; this may in turn undermine the information delivery effect of multimedia learning. Therefore, when employing multimedia materials in teaching, teachers must take into consideration the cognitive load being placed on learners and judge the amount of multimedia materials to be presented accordingly; multimedia technologies can also be integrated in a meaningful way accordingly to the teaching materials. In short, multimedia learning is an indispensable strategy in teaching and learning, and TMA is a suitable teaching design for application in PE teaching.

On the cognition level, learners may experience difficulties in the instantaneous comprehension of coherence between printed diagrams. This is because in printed diagrams, there is considerable information that must be processed; comprehension of coherence between printed diagrams involves the understanding of links between the various details of different pieces of information. Faraday and Sutcliffe [82] stated that appropriate integration of media and the utilization of different teaching approaches can promote information comprehension. In the process of cognition development, an individual starts with the development of cognition based on concrete experiences and slowly transitions to the development of abstract cognition. Accordingly, any teaching should be conducted on the basis of the previous learning experience of the target learner. The audiovisual information is later subjected to further processing by the learners and is thus sent to the short-term memory, later being systematically encoded to ease the delivery of the information to the long-term memory [80]. Therefore, using multimedia to deliver instructional information helps learners to organize and encode the meaning of received information and in turn eases the delivery of this information to the long-term memory; thorough and deep processing of the received information enhances learning performance. According to Dale [83], when new information is learned through the watching of dynamic videos, viewing of a relevant exhibition, and observation of a demonstrated instruction, a learning retention rate of $50 \%$ can be achieved. Similar perspectives can be found in studies on multimedia-learning theory by Mayer [15] and the theory of instruction by Bruner [84]; to successfully achieve learning objectives, teachers must begin with experience image representation (e.g., pictures and videos) and slowly transition toward symbolic representation (e.g., language and texts) in their teaching; this indicates that use of different media to simulate concrete entities can enhance the learning experience and help learners to learn more effectively. Multimedia learning thus offers diverse learning pathways for PE courses and offers possibility and flexibility for learners in terms of learning time, space, and methods. However, multimedia learning cannot completely replace traditional PE course design. If teachers can take their students' current cognitive development into consideration and assist the students to complete cognitive restructuring in the order of enactive representation, iconic representation, and symbolic representation, the students have a greater chance of developing true understanding of concepts in teaching materials and in turn achieve true learning. 


\subsection{Limitations of the study}

The teaching design ideology of the study is to discuss if TMA could be adopted to promote students' learning behavior and acquired knowledge of basketball game recording methods. The present study employed the nonequivalent pretest-post-test quasi-experimental design; yet, difficulties were encountered during actual implementation due to factors including the difficulty of acquiring a group sample, experimental mortality, lecture hours, and course progress and budgets. The research target of this study is limited to two classes of 4rd-year students in a university in Taiwan; in actual practice, one may only carefully infer the population. Thus, I would recommend to expand the research target's year of study, university, item and area to acquire a more complete research outcome.

\section{Conclusion and Recommendation}

This study investigated, with university students as the participants, the effect of TMA on acquired knowledge of basketball game recording methods and learning behavior in the subject of PE. The results indicated that the TMA intervention positively affected the participants' learning behaviors and knowledge. Although the study results revealed that both teaching approaches resulted in effective learning at the cognitive level, the participants subjected to TMA exhibited higher cognitive performance than those subjected to TT; this indicated that students may prefer to be taught using TMA. The study findings encourage teachers of physical education to teach students by using TMA as it improved the acquired knowledge of basketball game recording methods and learning behavior of students. Furthermore, the study suggested re-applying this research study by investigating the effect of TMA on other item from different physical education curriculum.

\section{$8 \quad$ References}

[1] Patterson, D. (2012). Building the case for culturally responsive teaching in physical education: Using high school students' perceptions toward multiethnic groups. Current Issues in Education, 15(3). http://cie.asu.edu/ojs/index.php/cieatasu/article/view/876

[2] Araujo, R., Mesquita, I., Hastie, P., Pereira, C. (2016). Students' game performance improvements during a hybrid sport education-step-game-approach volleyball unit. European Physical Education Review, 22(2): 185-200. https://doi.org/10.1177/1356336x15597927

[3] Wallhead, T., Garn, A.C., Vidoni, C., Youngberg, C. (2013). Game play participation of a motivated students during sport education. Journal of Teaching in Physical Education, 32(2): 149-165. https://doi.org/10.1123/jtpe.32.2.149

[4] Leser, R., Baca, A., Uhlig, J. (2011). Effectiveness of multimedia-supported education in practical sports courses. Journal of Sports Science \& Medicine, 10(1): 184-92.

[5] Huang, W.D. (2011). Evaluating learners' motivational and cognitive processing in an online game-based learning environment. Computers in Human Behavior, 27(2): 694-704. https://doi.org/10.1016/j.chb.2010.07.021 
[6] Papastergiou, M., Gerodimos, V. (2013). Can learning of basketball be enhanced through a web-based multimedia course? An experimental study. Education and Information Technologies, 18(3): 459-478. https://doi.org/10.1007/s10639-012-9186-Z

[7] Farias, C., Valério, C., Mesquita, I. (2018). Sport education as a curriculum approach to student learning of invasion games: Effects on game performance and game involvement. Journal of Sports Science \& Medicine, 17(1): 56.

[8] Weng, F., Yang, R.J., Ho, H.J., Su, H.M. (2018). A TAM-based study of the attitude towards use intention of multimedia among school teachers. Applied System Innovation, 1(3): 1-9. https://doi.org/10.3390/asi1030036

[9] Zhang, Y. (2018). Design and development of WEB-based remote network physical education teaching platform in Colleges and Universities. International Journal of Emerging Technologies in Learning (iJET), 13(4): 150-161. https://doi.org/10.3991/ijet.v13i04.8478

[10] Cairncross, S., Mannion, M. (2001). Interactive multimedia and learning: Realizing the benefits. Innovations in Education and Teaching International, 38(2): 156-164. https://doi.org/10.1080/14703290110035428

[11] Niegemann, H.M., Heidig, S. (2012). Multimedia learning. In N.M. Seel (Ed.), Encyclopedia of the sciences of learning (pp. 2372-2375), Boston, MA: Springer US. https://doi.org/10.1007/978-1-4419-1428-6_285

[12] Dai, W., Fan, L. (2012). Discussion about the Pros and Cons and recommendations for multimedia teaching in local vocational schools. Physics Procedia, 33: 1144-1148. https://doi.org/10.1016/j.phpro.2012.05.188

[13] Paivio, A. (1990). Mental representations: A dual coding approach. Vol. 9, New York, NYY: Oxford University Press.

[14] Baddeley, A. (1992). Working memory. Science, 255(5044): 556-559. https://doi.org/10. $1126 /$ science. 1736359

[15] Mayer, R.E. (2001). Multimedia learning, New York, NY: Cambridge University Press.

[16] Mayer, R.E., Moreno, R. (2003). Nine ways to reduce cognitive load in multimedia learning. Educational Psychologist, 38(1): 43-52. https://doi.org/10.1207/s15326985ep3801 6

[17] Dunlap, J.C., Lowenthal, P.R. (2016). Getting graphic about infographics: Design lessons learned from popular infographics. Journal of Visual Literacy, 35(1): 42-59. https://doi.org/10.1080/1051144x.2016.1205832

[18] Holzinger, A., Kickmeier-Rust, M.D., Albert, D. (2008). Dynamic media in computer science education; content complexity and learning performance: Is less more? Educational Technology \& Society, 11(1): 279-290.

[19] Ampa, A.T. (2015). The implementation of interactive multimedia learning materials in teaching listening skills. English Language Teaching, 8(12): 56-62. https://doi.org/10. 5539/elt.v8n12p56

[20] Chandler, P., Sweller, J. (1991). Cognitive load theory and the format of instruction. Cognition and Instruction, 8(4): 293-332. https://doi.org/10.1207/s1532690xci0804 2

[21] Paas, F., Tuovinen, J.E., Tabbers, H., Van Gerven, P.W. (2003). Cognitive load measurement as a means to advance cognitive load theory. Educational Psychologist, 38(1): 63-71. https://doi.org/10.1207/s15326985ep3801_8

[22] Sweller, J., Van Merrienboer, J.J., Paas, F.G. (1998). Cognitive architecture and instructional design. Educational Psychology Review, 10(3): 251-296. https://doi.org/10.1023/ a:1022193728205

[23] Gerjets, P., Scheiter, K. (2003). Goal configurations and processing strategies as moderators between instructional design and cognitive load: Evidence from hypertext-based instruction. Educational Psychologist, 38(1): 33-41. https://doi.org/10.1207/s15326985ep $\underline{38015}$ 
[24] Zhao, X., Wang, Y., Liu, Y., Xu, Y., Meng, Y., Guo, L. (2019). Multimedia based Teaching Platform for English Listening in Universities. International Journal of Emerging Technologies in Learning, 14(4): 160-168. https://doi.org/10.3991/ijet.v14i04.9690

[25] van Merriënboer, J.J., Sweller, J. (2010). Cognitive load theory in health professional education: Design principles and strategies. Medical Education, 44: 85-93. https://doi.org/10. $\underline{1111 / \mathrm{j} .1365-2923.2009 .03498 . \mathrm{x}}$

[26] Lou, M. (2017). Design of English multimedia teaching system based on diversification theory. International Journal of Emerging Technologies in Learning (iJET), 12(1): 119129. https://doi.org/10.3991/ijet.v12i01.6488

[27] Ding Y.L. (2011). Ergonomic, Beijing: Beijing Institute of Technology Press.

[28] Lin, J.H., Lu, F.J.H. (2013). Interactive effects of visual and auditory intervention on physical performance and perceived effort. Journal of Sports Science and Medicine, 12: 388393.

[29] Mitchell, D., Hutchinson, C.J. (2003). Using graphic organizers to develop the cognitive domain in physical education. Journal of Physical Education, Recreation \& Dance, 74(9): 42-47. https://doi.org/10.1080/07303084.2003.10608519

[30] Alstot, A.E. (2012). The effects of peer-administered token reinforcement on jump rope behaviors of elementary physical education students. Journal of Teaching in Physical Education, 31(3): 261-278. https://doi.org/10.1123/jtpe.31.3.261

[31] An, X. (2018) Innovative physical education methods based on computer technology. Educational Sciences: Theory \& Practice, 18(5): 2115-2123.

[32] Shen, B., McCaughtry, N., Martin, J.J., Fahlman, M., Garn, A.C. (2012). Urban highschool girls' sense of relatedness and their engagement in physical education. Journal of Teaching in Physical Education, 31(3): 231-245. https://doi.org/10.1123/itpe.31.3.231

[33] Laaser, W., Toloza, E.A. (2017). The changing role of the educational video in higher distance education. International Review of Research in Open and Distance Learning, 18(2): 1-10. https://doi.org/10.19173/irrodl.v18i2.3067

[34] Thomas, A. and Stratton, G. (2006). What are we really doing with ICT in physical education: A national audit of equipment, use, teacher attitudes, support and training? British Journal of Educational Technology, 37(4): 617-632. https://doi.org/10.1111/j.1467$\underline{8535.2006 .00520 . \mathrm{x}}$

[35] Castelli, D.M., Fiorentino, L. (2008). Physical education technology playbook, Champaign, IL: Human Kinetics.

[36] Cheon, J., Grant, M.M. (2012). The effects of metaphorical interface on germane cognitive load in web-based instruction. Educational Technology Research and Development, 60(3): 399-420. https://doi.org/10.1007/s11423-012-9236-7

[37] Kretschmann, R. (2012). What do physical education teachers think about integrating technology in physical education? European Journal of Social Sciences, 27(3): 444-448.

[38] Parton, G., Light, M. (2010). Using ICT to enhance learning in physical education. In R. Bailey (Ed.), Physical education for learning (pp. 129-144), London: Continuum.

[39] Kay, R. (2012). Exploring the use of video podcasts in education: A comprehensive review of the literature. Computers in Human Behavior, 28: 820-831. https://doi.org/10.1016/j.chb .2012 .01 .011

[40] McConville, S.A., Lane, A.M. (2006). Using on-line video clips to enhance self-efficacy toward dealing with difficult situations among nursing students. Nurse Education Today, 26(3): 200-208. https://doi.org/10.1016/j.nedt.2005.09.024

[41] Valle, A., Cabanach, R., Nunez, J., Gonzalez-Pienda, J., Rodriguez, S., Pineiro, I. (2003). Cognitive, motivational, and volitional dimensions of learning. Research in Higher Education, 44: 557-580. 
[42] Lawson, H.A. (2009). Paradigms, exemplars and social change. Sport, Education \& Society, 14(1): 97-119. https://doi.org/10.1080/13573320802615247

[43] Kirk, D. (2010). Physical education futures, London: Routledge.

[44] Kretschmann, R. (2015). Physical education teachers' subjective theories about integrating information and communication technology (ICT) into physical education. Turkish Online Journal of Educational Technology, 14(1): 68-96.

[45] Robinson, D., Randall, L. (2017). Gadgets in the gymnasium: Physical educators' use of digital technologies. Canadian Journal of Learning and Technology, 43(1): 1-21.

[46] White, R.K., Lippitt, R. (1960). Autocracy and democracy: An experimental inquiry, New York, NY: Harper \& Row.

[47] Connell, J.P., Wellborn, J.G. (1991). Competence, autonomy, and relatedness: A motivational analysis of self-system processes. In M.R. Gunnar, L.A. Sroufe (Eds.), Selfprocesses in development: Minnesota symposium on child psychology, Chicago, IL: University of Chicago Press.

[48] Chen, W.Y. (2001). Development of learning behavior inventory of physical education program. Archives of University Education and Sports, 90: 118-128.

[49] Luo, Y.J. (2019). The influence of problem-based learning on learning effectiveness in students of varying learning abilities within physical education. Innovations in Education and Teaching International, 56(1): 3-13. https://doi.org/10.1080/14703297.2017.1389288

[50] Bandura, A. (1997). Self-efficacy: The exercise of control, New York, NY: Macmillan Publishers.

[51] Gardner, R.C. (2006). The socio-educational model of second language acquisition: A research paradigm. Eurosla Yearbook, 6(1): 237-260. https://doi.org/10.1075/eurosla.6.14gar

[52] Kormos, J., Csizer, K. (2014). The interaction of motivation, self-regulatory strategies, and autonomous learning behavior in different learner groups. TESOL Quarterly, 48(2): 275299. https://doi.org/10.1002/tesq.129

[53] Tella, A. (2007). The impact of motivation on student's academic achievement and learning outcomes in mathematics among secondary school students in Nigeria. Eurasia Journal of Mathematics, Science \& Technology Education, 3(2): 149-156. https://doi.org/10.129 73/ejmste/75390

[54] Cole, M.S., Feild, H.S., Harris, S.G. (2004). Student learning motivation and psychological hardiness: Interactive effects on students' reactions to a management class. Academy of Management Learning \& Education, 3(1): 64-85. https://doi.org/10.5465/amle.2004.1243 $\underline{6819}$

[55] Oleson, A., Hora, M.T. (2014). Teaching the way they were taught? Revisiting the sources of teaching knowledge and the role of prior experience in shaping faculty teaching practices. Higher Education, 68(1): 29-45. https://doi.org/10.1007/s10734-013-9678-9

[56] Chen, R.S., Tu, C.C., Chiu, F.H. (2012). The impacts of the learning methods on webbased learning attitudes for university students: Taking a technology university as an example. International Journal on Digital Learning Technology, 4(3): 35-59.

[57] Pintrich, P.R. (2000). Multiple goals, multiple pathways: The role of goal orientation in learning and achievement. Journal of Educational Psychology, 92(3): 544. https://doi.org/10.1037//0022-0663.92.3.544

[58] Solak, E., Cakir, R. (2015). Exploring the effect of materials designed with augmented reality on language learners' vocabulary learning. Journal of Educators Online, 12(2): 50-72. https://doi.org/10.9743/jeo.2015.2.5

[59] Berger, J.L., Karabenick, S.A. (2011). Motivation and students' use of learning strategies: Evidence of unidirectional effect $s$ in mathematics classrooms. Learning and Instruction, 21(3): 416-428. https://doi.org/10.1016/j.learninstruc.2010.06.002 
[60] Carlson, T.B. (1995). We hate gym: Student alienation from physical education. Journal of Teaching in Physical Education, 14: 467-477. https://doi.org/10.1123/jtpe.14.4.467

[61] McKenzie, T.L., Alcaraz, J.E., Sallis, J.F. (1994). Assessing Children's liking for activity units in an elementary school physical education curriculum. Journal of Teaching in Physical Education, 13: 206-215. https://doi.org/10.1123/itpe.13.3.206

[62] Silverman, S., Subramaniam, P.R. (1999) Student attitude toward physical education and physical activity: A review of measurement issues and outcomes. Journal of Teaching in Physical Education, 19: 97-125. https://doi.org/10.1123/itpe.19.1.97

[63] Subramaniam, P.R., Silverman, S. (2007). Middle school students' attitudes toward physical education. Teaching and Teacher Education, 23(5): 602-611. https://doi.org/10.1016/j. tate.2007.02.003

[64] McKenzie, T. (2003). Health-related physical education: Physical, activity fitness, and wellness. In S.J. Silverman, C.D. Ennis (Eds.), Student learning in physical education: Applying research to enhance instruction (pp, 207-226), Champaign, IL: Human Kinetics.

[65] Canan Koca, F., Asci, H., Demean, G. (2005). Attitudes toward physical education and class preferences of Turkish adolescents in terms of school gender composition. Adolescence, 40(158): 366-375.

[66] Portman, P.A. (2003). Are physical education classes encouraging students to be physically active? Experiences of ninth graders in their last semester of required physical education. Physical Educator, 60(3): 150.

[67] Stromso, H.I., Braten, I. (2010). The role of personal epistemology in the self-regulation of internet-based learning. Metacognition and Learning, 5(1): 91-111. https://doi.org/10.10 07/s11409-009-9043-7

[68] Jansson, G. (2006). Recontextualisation processes as sense-making practice in student writers' collaborative dialogue. Studies in Higher Education, 31(6): 667-688. https://doi.org/10.1080/03075070601004275

[69] Wen, M.L., Tsai, C.C. (2006). University students' perceptions of and attitudes toward (online) peer assessment. Higher Education, 51(1): 27-44. https://doi.org/10.1007/s10734$\underline{004-6375-8}$

[70] FIBA (2018). Official basketball rules. Available from URL: http://www.fiba.basketball/ documents/official-basketball-rules.pdf https://doi.org/10.35532/jsss.v3.093

[71] Rosenshine, B. (1983). Teaching functions in instructional programs. The Elementary School Journal, 83(4): 335-351. https://doi.org/10.1086/461321

[72] Kao, C.C. (2012). A study on influences from student team achievement division to basketball strategy cognition and learning motivation. Taiwan Society for Sport Pedagogy, 7: 23-40.

[73] Kao, C.C., Yang, J.L. (2015). Affect the ability of creative problem solving and cooperative learning strategies of intervention strategies for basketball cognitive, physical education learning attitude and problem solving, Taipei: Ming Chuan University.

[74] Cohen, J. (2013). Statistical power analysis for the behavioral sciences, New York, NY: Routledge.

[75] Bennett, G. (2002). Web-based instruction in sport management. Sport Management Review, 5: 45-68. https://doi.org/10.1016/s1441-3523(02)70061-2

[76] Brown, J.S., Collins, A., Duguid, P. (1989). Situated cognition and the culture of learning. Educational Researcher, 18(1): 32-42. https://doi.org/10.3102/0013189x018001032

[77] Milos, L., Vojkan, V., Srecko, S., Jelena, V. (2014). Using supplementary video in multimedia instruction as a teaching tool to increase efficiency of learning and quality of experience. The International Review of Research in Open and Distributed Learning, 15(3). https://doi.org/10.19173/irrodl.v15i3.1825 
[78] Antoniou, P., Derri, V., Kioumourtzoglou, E., Mouroutsos, S. (2003). Applying multimedia computer-assisted instruction to enhance physical education students' knowledge of basketball rules. European Journal of Physical Education, 8(1): 78-90. https://doi.org/10. 1080/1740898030080106

[79] Vernadakis, N., Zetou, E., Tsitskari, E., Giannousi, M., Kioumourtzoglou, E. (2008). Student attitude and learning outcomes of multimedia computer-assisted versus traditional instruction in basketball. Education and Information Technologies, 13(3): 167-183. https://doi.org/10.1007/s10639-008-9061-0

[80] Mayer, R., Mayer, R.E. (2005). The Cambridge handbook of multimedia learning, Cambridge, MA: Cambridge University Press.

[81] Papastergiou, M., Pollatou, E., Theofylaktou, I., Karadimou, K. (2014). Examining the potential of web-based multimedia to support complex fine motor skill learning: An empirical study. Education and Information Technologies, 19(4): 817-839. https://doi.org/10.10 07/s10639-013-9256-X

[82] Faraday, P., Sutcliffe, A. (1997). Designing effective multimedia presentations. Proceedings of the ACM SIGCHI Conference on Human Factors in Computing Systems. New York, NY: ACM. https://doi.org/10.1145/258549.258753

[83] Dale, E. (1946). Audio-visual method sin teaching, New York, NY: Holt, Rinehart, \& Winston.

[84] Bruner, J.S. (1966). Toward a theory of instruction, Cambridge, MA: Harvard University Press.

\section{Authors}

Chun-Chieh Kao is an Associate Professor of Physical Education in Ming Chuan University, Taiwan. Ph. D. candidate in Shanghai University of Sport presently. kao@mail.mcu.edu.tw (C. C. Kao)

Yu-Jy Luo is an Associate Professor of Physical Education in Ming Chuan University, Taiwan. Ph. D. candidate in Shanghai University of Sport presently. anitaluo@mail.mcu.edu.tw (Y. J. Luo)

Article submitted 2019-07-28. Resubmitted 2019-09-22. Final acceptance 2019-09-22. Final version published as submitted by the authors. 